\title{
Trends in flow intermittence for European Rivers
}

Yves Tramblay ${ }^{1}$, Agnieszka Rutkowska $^{2}$, Eric Sauquet ${ }^{3}$, Catherine Sefton ${ }^{4}$, Gregor Laaha ${ }^{5}$, Marzena Osuch ${ }^{6}$, Teresa Albuquerque ${ }^{7}$, Maria Helena Alves ${ }^{8}$, Kazimierz BANASIK ${ }^{9}$, Aurelien Beaufort ${ }^{3}$, Luca Brocca ${ }^{10}$, Stefania Camici ${ }^{10}$, Csabai Zoltán ${ }^{11}$, Hammouda Dakhlaoui $^{12}$, ANNA MARIA DE GIROLAMO ${ }^{13}$, Gerald Dörflinger ${ }^{14}$, Francesc Gallart ${ }^{15}$, Tobias Gauster ${ }^{5}$, Lahoucine Hanich ${ }^{16}$, Silvia Kohnova ${ }^{17}$, Luis Mediero ${ }^{18}$, Ninov Plamen ${ }^{19}$, Simon Parry ${ }^{20}$, Pere Quintana-Seguí ${ }^{21}$, Ourania Tzoraki ${ }^{22}$, and Thibault Datry ${ }^{23}$

${ }^{1}$ HydroSciences Montpellier

${ }^{2}$ University of Agriculture

${ }^{3}$ INRAE

${ }^{4} \mathrm{UKCEH}$

${ }^{5}$ University of Natural Resources and Life Sciences, BOKU Vienna,

${ }^{6}$ Institute of Geophysics PAS

${ }^{7}$ University of Évora, Portugal

${ }^{8}$ Portuguese Environment Agency

${ }^{9}$ Warsaw University of Life Sciences - SGGW

${ }^{10}$ National Research Council

${ }^{11}$ University of Pécs, Hungary

${ }^{12}$ Ecole Nationale des Ingénieurs de Tunis, University of Tunis El Manar

${ }^{13}$ Water Research Institute, National Research Council, Bari, Italy

${ }^{14}$ Cyprus Ministry of Agriculture Natural Resources and Environment Water Development Department

${ }^{15} \mathrm{CSIC}$

${ }^{16}$ Faculté des Sciences et Techniques Guéliz, Université Cadi Ayyad

${ }^{17}$ Slovak University of Technology

${ }^{18}$ Polytechnic University of Madrid Superior Technical School of Agricultural Engineering

Food Science and Biosystems

${ }^{19}$ Bulgarian Academy of Science, Sofia, Bulgaria

${ }^{20}$ Centre for Ecology \& Hydrology

${ }^{21}$ Universitat Ramon Llull - CSIC

${ }^{22}$ University of the Aegean, Greece

${ }^{23}$ National Research Institute of Science and Technology for Environment and Agriculture

May 5, 2020

\begin{abstract}
Intermittent rivers are prevalent in many countries across Europe and in Mediterranean countries outside Europe, but little is known about the temporal evolution of intermittency characteristics and their relationships with climate variability. In this study, a trend analysis is performed on the annual and seasonal number of zero-flow days, the maximum duration of dry
\end{abstract}


spells and the mean date of the zero-flow events, on a database of 452 rivers in European and in Mediterranean countries outside Europe, with varying degrees of intermittence. In addition, the relationships between flow intermittence and climate are investigated using the Standardized Precipitation Evapotranspiration Index (SPEI) and six climate indices describing large scale atmospheric circulation. Results indicated a strong spatial variability of the seasonal patterns of intermittence and the annual and seasonal number of zero-flow days, which highlights the controls exerted by local catchment properties. Most of the detected trends indicate an increasing number of zero-flow days which also tend to occur earlier in the year, in particular in Southern Europe. The SPEI is found to be strongly related to the annual and seasonal zero-flow day occurrence in more than half of the stations for different accumulation times between 12 and 24 months. Conversely, there is a weak dependence of river intermittence with large-scale circulation indices. Overall, these results suggest increased water stress in intermittent rivers that may affect their biota and biochemistry and also reduce available water resources.

\section{INTRODUCTION}

In streams and rivers, flow intermittence is characterized by the cessation of flow, followed or not by complete drying of the channels (Datry et al. 2016). The spatio-temporal patterns of flow intermittence can be extremely variable depending on climatic, geologic or topographic contexts (Costigan et al. 2017). While many studies have been focused on river low-flows characterization and, in particular, the possible long-term trends due to climate change (e.g., Marx et al., 2018), far less work has been dedicated to intermittent rivers and ephemeral streams. Recent studies indicate trends towards less severe climatic droughts over NorthEastern Europe, especially in winter and spring, and the opposite in Southern Europe where more severe droughts, are encountered (Gudmundsson and Seneviratne, 2015, Spinoni et al., 2017, Hertig and Tramblay, 2017). Globally, negative trends in streamflow in Europe have been reported by Stahl et al. (2010) and Blöschl et al. (2019), in Spain by Gallart and Llorens (2004), Coch and Mediero (2016), in Italy by De Girolamo et al. (2017), Germany by Bormann and Pinter (2017) and in Cyprus by Myronidis et al. (2018).

To our knowledge, no studies have explored the trends in flow intermittence across Europe. Snelder et al. (2013) analyzed French patterns in flow intermittence, using as indicators the mean annual frequency of zero flow periods and the mean duration of zero flow periods. Unsurprisingly, the highest values of the two characteristics coincided with the years of severe droughts. Besides climate influences, intermittence characteristics might be strongly influenced by processes operating at small scales, such as groundwatersurface water interactions and transmission losses (Beaufort et al., 2019, Costigan et al. 2017). Similarly, in different regions of the USA, Eng et al. (2015) classified 265 intermittent streams using as descriptors the number of zero-flow events, the median discharge and the $10^{\text {th }}$ percentile of daily flows, and they showed strong dependency of these metrics with temporal variations of precipitation and evapotranspiration. More generally, the probability of flow intermittence in rivers worldwide is likely to increase with the projected rise of temperature in future climate scenarios (Döll \& Schmied 2012, Osuch et al., 2016, 2018, Snelder et al. 2013, Eng et al. 2015).

Previous classifications of European rivers based on their flow regime have usually not integrated flow intermittence, or in a relatively small sample of basins (Gallart et al., 2010, Oueslati et al., 2015). This is probably due to the difficulties in conceptually defining the intermittent, ephemeral and perennial states of streams (Gustard et al., 1992, Oueslati et al., 2015, Delso et al., 2017). For low flows and droughts, regional classifications at the European scale (Stahl and Demuth, 1999, Hannaford et al., 2010, Kirkby et al., 2011) or national scale (in Spain, Coch and Mediero, 2016) have been produced using most often the flow exceeded $90 \%$ of the time as a threshold for low flows or drought periods. Only a few classifications of intermittent rivers based on zero flow indicators have been proposed, in an attempt to relate their spatiotemporal variability with catchment characteristics or climatic variability (Kennard et al., 2010, Snelder et al., 2013, Eng et al., 2015, Perez-Saez et al., 2017, Tzoraki et al., 2016, De Girolamo et al., 2014, Dörflinger, 2016, Pournasiri Poshtiri et al., 2019). Identifying homogeneous regions and the drivers of flow intermittence, in terms of seasonality, catchment or climatic properties, could help to estimate intermittence characteristics and trends at the regional level (Pournasiri Poshtiri et al., 2019). Indeed, these intermittent and ephemeral streams are underrepresented in monitoring networks and often ungauged in Europe (Skoulikidis et al., 2017, Costigan et al., 2017). 
Besides catchment characteristics, large scale climate variability may also exert an influence on intermittence patterns. Giuntoli et al. (2013) evaluated the relationships between low flows and large-scale climate variability in France, using climate indices such as the North Atlantic Oscillation (NAO), the Atlantic Multidecadal Oscillation (AMO) and a weather typing approach. Their results indicated an increase of drought severity in Southern France, and the usefulness of lagged climate indices as predictors of summer low flows. Indeed, approaches based on weather typing or composite analysis with climatic data could help to evaluate the synoptic ingredients associated with dry periods and their long-term evolution and trends (Stahl and Demuth, 1999, Beck et al., 2015, Ionita et al., 2017). For the summer 2015 drought episode that hit large parts of Europe, Ionita et al. (2017) observed that this event was associated with positive anomalies in 500 $\mathrm{hPa}$ geopotential height and Mediterranean Sea surface temperatures. Since these climatic drivers are likely to have different influences in different regions of Europe, there is a need to perform such analysis at the regional scale.

The objectives of this study are: (i) to analyze the seasonal characteristics of flow intermittence in Europe, (ii) to test temporal trends in the number of zero-flow days at annual and seasonal scale and (iii) to analyze the possible relationships between the occurrence of zero-flows and climate indices. This study relies on an unprecedented database of intermittent rivers across Europe, which is presented in the next section, the methodology is presented in section three and the results in section four.

\section{DATABASE OF INTERMITTENT RIVERS}

The database of discharge time series of ephemeral and intermittent streams have been collected in the framework of the SMIRES COST action (Datry et al., 2017) in the different European countries in addition to individual contributions and stations from the GRDC (https://www.bafg.de/GRDC) database including countries outside of Europe such as Morocco, Tunisia and Israel. The selected rivers are characterized by natural or moderately influenced regime, and catchment area smaller than $2000 \mathrm{~km} 2$. The absence of dams or reservoirs upstream of the station gauge has been verified from a GIS analysis using the GRanD database (http://globaldamwatch.org/grand/). The metadata originating from different countries should be analyzed with care and can be misleading since the definition of "natural", and the distinction between "little influenced" and "heavily" influenced rivers may vary strongly between different countries. Also, since this study is focusing on zero-flow days, it is possible that zero values are put in place of missing data; this is the reason why the data had to be checked carefully in the absence of metadata for many rivers.

Instead of using zeros, a threshold of $10^{-4} \mathrm{~m}^{3} \mathrm{~s}^{-1}\left(0.1 \mathrm{~L} \mathrm{~s}^{-1}\right)$ is considered to identify zero-discharge days to account for measurements errors of very small discharge values. However other thresholds, such as $5 \mathrm{~L}$ $\mathrm{s}^{-1}$ recommended by Gustard et al. (1992) or Delso et al. (2017) have also been tested, yielding similar results. In addition, the individual time series have been checked to verify if the smallest reported non-zero flows were below $10 \mathrm{~L} \mathrm{~s}^{-1} \mathrm{l} / \mathrm{s}$. If there were no non-zero flows below $10 \mathrm{~L} / \mathrm{s}$ in a series, the zero flows of that series were interpreted as wrongly reported missing values. The analyses performed in the present work are focusing on the annual and seasonal timescales, a hydrological year starting April 1 through March 31, and considering summer from April to September and winter from October to March, since this is common practice in low-flow analysis. The definition of the hydrological years was governed by a preliminary analysis on the seasonality of zero-flow events in Europe (mainly in summer and autumn but also in winter). This reduces the chance of observing a flow event in two consecutive hydrological years. The database includes 452 stations with at least two years with five consecutive zero-flow days. This criterion has been chosen to avoid including in the database some missing data in place of actual river intermittence, since it is unlikely that river flow will cease only one day in one year. Indeed, if for an annual time series only a single day with zero-flow is recorded, it could be missing data not properly reported in the metadata. For all stations, all years with more than $5 \%$ missing data have been removed. Across most stations (452), there is a common period for analysis between 1970 and 2010 when data are available. Two annual and seasonal metrics of duration, - the duration of the longest no-flow event (maximum length of zero-flow days) and the total duration of no-flow days (sum of zero-flow days) - and the mean date of no-flow days were studied too.

\section{METHODS}




\subsection{Clustering of stations based on seasonality measures}

Directional statistics can be used to define similarity measures from the timing of zero flow conditions. The first step is to convert dates into the day-in-year, which is the day of a year starting from 1 April, into an angular value (Burn, 1997):

$\theta_{i}=(\text { Julian Date })_{i}\left(\frac{2 \pi}{365}\right)(1)$

where $\vartheta_{\imath}$ is the angular value in radians for the zero-discharge day $I$ In leap years, the denominator was increased by one. All zero-discharge days can then be seen as vectors with unit magnitude and direction given by $\vartheta_{l}$. Then, for a sample of $n$ dates, the and coordinates of the mean date can be determined as:

$\bar{x}=\frac{1}{n} \sum_{i=1}^{n} \cos \left(\theta_{i}\right)(2)$

$\bar{y}=\frac{1}{n} \sum_{i=1}^{n} \sin \left(\theta_{i}\right)(3)$

The mean direction (the mean date) $\in[0,2 \pi)$ of zero-flow dates for a given station can be then obtained from:

$\underline{j}=\arctan ^{*}\left(\frac{y}{x}\right)(4)$

where $\arctan ^{*}()$ is the quadrant-specific inverse of the tangent function. The measure of the variability of the $n$ occurrences around the mean date is the mean resultant length:

$\underline{r}=\sqrt{\underline{x}^{2}+\underline{y}^{2}}(5)$

It should be noted that $0<\leq 1$ and that near to 1 implies little variation and high concentration of data, and near to 0 a large variation and wide dispersion around the mean date.

The clustering is based on the and metrics calculated for winter and summer, using the Ward distance. The identification of the optimal number of clusters is achieved with the help of the silhouette plot and visual inspection of the clusters obtained.

\subsection{Trend analysis}

Trend analysis has been performed using the modified Mann-Kendall (MK) test (Mann, 1945, Hamed and Rao, 1998) on the annual and seasonal metrics of duration and occurrence and the mean date of occurrence . The MK rank correlation test for two sets of observations $X=x_{1}, x_{2}, \ldots, x_{n}$ and $Y=y_{1}, y_{2}, \ldots, y_{n}$ is formulated as follows, with the $\mathrm{S}$ statistic calculated as:

$S=\sum_{i<j} a_{\mathrm{ij}} b_{\mathrm{ij}}(6)$

where

$a_{\mathrm{ij}}=\operatorname{sgn}\left(x_{j}-x_{i}\right)=\{$

1, if $x_{i}<x_{y}$

0 , if $x_{i}=x_{y}$

-1 , if $x_{i}>x_{y}$

and $b_{i j}$ is similarly defined for the observations in $Y$. Under the null hypothesis that $X$ and $Y$ are independent and randomly ordered, the statistic $S$ tends to normality for large $n$. In the current work, the modified MK test proposed by Hamed and Rao (1998) is considered, that is robust in the presence of autocorrelation in the time series tested by modifying the variance of the $S$ statistic.

In addition, to consider the issue of false positives due to repeated statistical tests (Wilks, 2016), the False Discovery Rate (FDR) procedure introduced by Benjamini and Hochberg (1995) has been implemented to identify field-significant test results. With this method, the results are considered field significant (or regionally significant) if at least one local p-value of the test is below the global significance level. Only 254 
of the 452 selected stations, those with at least 10 years with more than five consecutive zero-flow days, have been considered for this analysis to avoid testing trends on very small sample size.

\subsection{Relationships with climate}

To estimate the relationships between dry spells and climatic drivers, namely precipitation and evapotranspiration, the correlation between the annual and seasonal sum of zero flow days and the maximum length of zero-flow days with the Standardized Precipitation-Evapotranspiration Index (SPEI, Vicente-Serrano et al., 2010) was analyzed with the Spearman correlation coefficient (rho). The SPEI uses the monthly difference between precipitation and potential evapotranspiration; thus it represents a simple climatic water balance, which can be calculated at different time scales similarly to the Standardized Precipitation Index (SPI, McKee et al., 1993). The SPEI with 6, 12, 18 and 24 months aggregation time have been downloaded from the CSIC Global SPEI database ( https://spei.csic.es/database.html). The SPEI values were computed using monthly sum of precipitation and potential evapotranspiration at 0.5 degrees spatial resolution and a monthly time resolution from the Climatic Research Unit (CRU) of the University of East Anglia. Version 3.23 of the CRU dataset has been used to compute the SPEI. The SPEI computation is based on the FAO-56 Penman-Monteith estimation of potential evapotranspiration. The details of the SPEI computation were presented by Beguería et al. (2014). For each station, the value was extracted from the SPEI grid cell covering the station, since the size of the basins considered is small $\left(<2000 \mathrm{~km}^{2}\right)$ compared to the CRU mesh (approximately $2500 \mathrm{~km}^{2}$ ) used as a basis for the calculation of the SPEI.

In addition, different climate indices describing large scale atmospheric circulation patterns have been selected: the North Atlantic Oscillation (NAO), the Atlantic Multi-decadal Oscillation (AMO), the Mediterranean Index (MOI), the East Atlantic Western Russia (EAWR), the Pacific Decadal Oscillation (PDO), and the Scandinavian Index (SCAND). The time series for these indices have been retrieved from the CPC database available online at:https://www.cpc.ncep.noaa.gov. The annual, winter and summer mean values were used. For NAO, the seasonal three-month DJF, MAM, JJA, and SON values were also included to account for its within-year variability.

\section{RESULTS}

\subsection{Spatiotemporal patterns and seasonality}

Figure 1 shows that for a large number of stations, there are only a small number of years with more than $10 \%$ zero-flow days. Only a few stations have zero-flow $90 \%$ of the years with available data. As shown on the map (Figure 1), the annual percentage of years with zero-flow days can vary strongly even for neighboring stations. This highlights the influence of local characteristics (geology, land cover, water use...) on zero flow occurrences. Snelder et al. (2013) previously observed over France that the high spatial heterogeneity in small-scale processes associated with intermittence partly explains the low spatial synchronization of zeroflows. There is a weak latitudinal gradient in the occurrence of zero-flow days, with the higher mean annual number of zero-flow days in the South (rho $=-0.36$ with latitude, significant at the $5 \%$ level), but with a very strong spatial variability even for neighboring catchments. This implies that most intermittent streams are not necessarily associated with the aridest climate conditions in Southern Europe.

Clustering has been applied using the variables $\vartheta$, the mean direction of zero-flow and the variability around this date, $r$, computed for the winter and summer seasons. As shown in Figure 2, three different seasonality patterns were identified. The largest one, Cluster 2, is composed of 376 stations having a mean date of occurrence for zero-flow days between May and November, at the end of summer. The location of the stations composing this cluster are scattered all across Europe, in different climatic zones ranging from Continental to Mediterranean climate types. The second-largest cluster, Cluster 3, contains 47 stations with a mean occurrence of no-flow events between January and March. It includes stations with a nival regime, such as the Pyrenees of Scandinavia, that experience cessation of flow due to freezing. The Cluster 1 (29 stations) mean corresponds to late fall (November to January). As shown in this analysis, for most stations (Clusters 1 and 3), the zero-flow conditions are more frequently observed in summer months or during winter or early spring due to snow and ice cover. Yet, as shown in the map in Figure 2, there are no clear spatial 
patterns that could be identified from this analysis though Cluster 3 stations are located predominantly in mountainous or northern areas.

\subsection{Trend analysis}

The trend detection and subsequent analyses have been performed only for the 254 rivers with at least 10 years with a minimum of 5 consecutive zero-flow days. First trend analysis has been carried out on annual, winter and summer mean dates of zero-flow occurrence, with the metric (eq. 4) computed on an annual or seasonal basis. The results in terms of significant trends are shown in Figure 3, indicating for most rivers in southern Europe a trend towards earlier occurrence in zero-flow days, mostly for the annual and summer timescales. For the river in the Baltic region, the trend toward later occurrence in zero-flow days for the summer and annual periods can be observed. Conversely, more contrasted trends patterns are detected for winter, with both positive and negative trends in the mean date for stations, but close to each other. A significant increasing trend is visible in southern France and central Spain for the winter period.

The second trend analysis is concerning annual and seasonal sums and maximum lengths of zero-flow days, the results are presented in Table 1 and figure 4 . At the annual scale, 60 stations (24\%) have positive trends in the number of zero flow days and more generally there are more positive trends detected by comparison to the negative trends for all indicators. Since on average the trends affect about $34 \%$ of stations, these trends (both positive and negative) are all field-significant according to the FDR procedure. These results indicate that at the annual and seasonal timescales the majority of trends are towards an increase in dryness. At the seasonal timescale, there is a marked trend towards an increase in summer zero-flows, but fewer trends detected for winter. Overall, fewer trends are detected for extreme durations compared to annual or seasonal totals, with the notable exception of the winter maximum lengths of zero-flow days that are increasing in the majority of stations.

\subsection{Links with SPEI anomalies}

In this section, the findings of the relationships between the occurrences of zero-flow days and SPEI anomalies are presented. In the first step, a trend analysis has been performed on SPEI over the different basins for different aggregation periods with $6,12,18$ and 24 months. The results show a clear pattern with positive trends at stations located north of $45^{\circ} \mathrm{N}$ and negative trends in the south, such findings are fully consistent with Spinoni et al. (2017). To check if the SPEI anomalies could be explanatory covariates for the inter-annual variability of zero-flow day occurrences, the SPEI with different aggregation time has been correlated with the number of zero-flow days and the maximum dry spell lengths. Since it has been shown previously that these variables and SPEI may exhibit trends, the time series have been de-trended in the cases where significant trends were found. Results show a strong association of zero-flow days with SPEI anomalies in particular at the annual and summer timescales (Figure 5), with a lower number of significant correlations during winter. The annual or seasonal sums of zero-flow days are more strongly associated with SPEI anomalies than the maximum length of dry spells, a metric that is probably strongly affected by the hydrogeology and the memory of the basins. Figure 6 shows the map of correlation coefficients obtained with the SPEI18. The correlations are negative for all SPEI timescales, indicating that negative SPEI anomalies, i.e. pronounced precipitation deficits, are linked with a larger number of zero-flow days. For about one-third of stations $(36 \%)$ there is no significant correlation these stations are mostly located in Spain, southern France, North Africa, Cyprus, but also Belgium. A strong spatial variability of the pattern is once again evident basins indicating local influences. The strength of the correlations is higher for basins with a larger annual average number of zero-flow days for almost all indicators. This demonstrates that strongly intermittent basins are more influenced by climatic variations to determine the annual number of zero-flow days. This is probably due to the fact that these catchments are often close to the wet/dry threshold and consequently immediately impacted by a variation of precipitation availability. There is also statistically significant, but moderate $(\mathrm{rho}=0.2)$, the correlation between the strength of the correlations with the SPEI12 and basin size, indicating that the influence of SPEI12 might be stronger for smaller basins since larger basins can be more influenced by human activities. Yet, this relationship is not significant for the SPEI18 and SPEI24. Smaller basins have a reduced buffer capability in the context of climate variability so this behaviour is expected. 


\subsection{Relations with large-scale atmospheric circulation}

As the large scale climate drivers have high- and/or low-frequency time variability, the correlation analysis should consider long time series. That is why only rivers with at least 30 years of data during 1970-2010 have been examined. AMO and NAO are the most influential. At the annual scale, the AMO was the driver with positive correlations for a considerably high percentage of catchments, $21 \%$ for the longest annual noflow event and $23 \%$ for the annual sum. Results for both metrics in seasons are presented in Table 2. The summer and the winter AMO are the drivers with the strongest links to the summer and winter metrics. The cluster of rivers positively associated with the winter AMO is well recognizable in northern Europe (Norway, Finland) for both winter metrics. The belt comprising Great Britain and south Sweden with a negative link between the winter AMO and the winter sum is noticeable. A similar pattern is observed for the summer and the annual AMO (Figure 7). Additionally, the southern, Mediterranean part of Europe might be positively influenced by the AMO. The conclusion can be drawn that the AMO is a potential driver of the intermittence and that its influence can be stretched to the following season. The associations with the NAO are less frequent. However, the apparent cluster of rivers with a negative link to the NAO DFJ can be observed in the Scandinavian Peninsula for both winter metrics (Figure 7). The rivers positively linked to JJA NAO are scattered over Europe. It is worth emphasizing that this large scale climate effect can be hidden by more local climate conditions.

The relationship between climate drivers and hydrological characteristics in Europe has been documented by many researchers (e.g., Valty et al. 2015, Wrzesiński \& Paluszkiewicz 2011). Results of the analysis are to a large extent consistent with results obtained by Giuntoli et al. (2013) where positive links between the annual discharge volume deficit and the annual NAO and AMO were revealed in many rivers in France, providing insights into the increase of drought severity. Results are also consistent with Linderholm et al. (2009) who reconstructed the summer NAO since the $19^{\text {th }}$ century and revealed strong links to droughts in the Eastern Atlantic region from a multi-century perspective. Results are similar to Hurrell and Folland (2002) who showed that the NAO, apart from its worldwide importance in shaping the winter hydrological conditions, can affect the summer hydrological conditions and might force droughts.

\section{DISCUSSION AND CONCLUSIONS}

This study provides the first European-scale assessment of the trends in intermittence over the last decades. The most striking results are (i) the strong spatial variability of the detected trends, and (ii) the seasonality and relationships with climate drivers. Overall, there is a considerable spatial variability of flow intermittence, with possibly strong dependencies of the different indicators with basin characteristics. Most of detected trends are towards an increasing number of zero-flow days, tending to occur earlier in the season, in particular around the Mediterranean basin. For most basins, there is a strong association of zero-flow days with SPEI negative anomalies, but neighboring basins may exhibit different relationships showing again the strong spatial variability. This implies that regional predictions or generalizations for flow intermittence patterns should be interpreted with caution. Any mapping or extrapolation from such regional results may be prone to considerable errors if not considering basin characteristics that are likely to play a strong role in determining flow intermittence properties. In this study, the individual catchment characteristics (ie. topography, geology, land use, soil types) have not been analyzed, which would require a major work at such a continental-wide scale. In particular, it would be particularly interesting to distinguish basins with strong surface-groundwater interactions that could explain some of the patterns described in the present study. However, as noted by Snelder et al. (2013), flow intermittence is also controlled by processes operating at scales smaller than catchments, thus capturing these processes would require a much more detailed investigation than classical regional approaches to take into account the local physiographic characteristics (Tramblay et al., 2010).

A major uncertainty of the present work and, to a greater extent, applicable to all ecohydrological research on intermittent rivers is the definition of the zero-flow days and the lack of regional representativeness of the monitoring networks. With regard to the first aspect, there is a wide variety of measurements procedures in different European countries, leading to different accuracy of the measured discharge values, in particular the minimal values. For example, in the UK or in France the data is provided in $\mathrm{m}^{3} \mathrm{~s}-1$ with an accuracy of three 
decimals, but for many other countries, the minimum reported discharge is sometimes much greater than 1 L s-1 due to different measuring methods. In addition, many rating curves at open channel stations have uncertainty at low flows caused by instability of the riverbed. In the present work, we considered a strict criterion to identify zero-flow days, but a more adequate selection could be made possible if good quality metadata information were available for most rivers, which is not currently the case for several countries. With regard to the second aspect of regional representativeness, several studies have highlighted the lack of measurements for intermittent rivers (Skoulikidis et al., 2017, Costigan et al., 2017). The number of monitored head water streams which are likely to be intermittent is indeed much smaller than the number of perennial and large streams in national and international databases, although their contribution to the water resources is probably high. This questions the rationale behind national measurement strategies for intermittent streams, in particular, the most ephemeral ones, since they present a possibly reduced interest in water resources management by comparison to perennial streams. Depending on the national monitoring strategies of the river network, it is possible that the selection of intermittent rivers to be monitored may be biased towards a specific type of rivers within a given geographic location of geological properties.

Another important aspect to take into consideration is the regulation status of the monitored rivers, which may evolve over time and not be available in the stations' metadata. In the present work, the selected basins are those described as natural or weakly altered based on their metadata information. Yet, how to quantitatively define "weakly altered" between different national networks and monitoring protocols? This definition may differ from one country to another without a common objective criterion to define the percentage of natural discharge being diverted or used for water supply. Besides river alterations, often assumed to be an expert judgement, the quantitative evaluation of the water uptake would require extensive work to monitor and collect water consumption data over time. Even for a river considered to be unaltered, diffuse groundwater pumping may occur and therefore have impacts on the groundwater-surface interactions, which could in turn strongly impact intermittence occurrence. Two examples of the influence of river status as described in the metadata on the trends results may be found in the UK. The Coal Burn River is classified as broadly natural, but is an experimental catchment set up to assess the impact of afforestation and the trend analysis indicates an increase in zero-flow days, showing that the influence of land-use change might indeed be significant on this aspect of the flow regime. The limestone Slea River that conversely experienced a decrease in zero-flow days was also classified as natural, but further scrutiny revealed a discharge augmentation scheme installed in 1995. Taking into account all these local specificities in addition to the available metadata would require tremendous effort and the information may not always be as readily available. The main findings of the present study are an incentive to implement process-based studies on the intermittency characteristics for different climatic and physiographic environments.

\section{Acknowledgements}

This research is part of the COST action CA15113 SMIRES, Science and Management of Intermittent Rivers and Ephemeral Streams https://www.smires.eu/, a short term scientific mission has been funded for A. Rutkowska. A. Rutkowska was also supported by the Ministry of Science and Higher Education of the Republic of Poland (grant DS 3371). The different data providers are gratefully acknowledged. Some of the station data was retrieved from the Global Runoff Data Centre (56068 Koblenz, Germany).

\section{Data Availability Statement}

The different indexes computed in the present work are made available to the community for research applications upon request to the first author.

\section{References}

Beaufort, A., Carreau, J., \& Sauquet, E., (2019). A classification approach to reconstruct local daily drying dynamics at headwater streams. Hydrological Processes, 33, 1896- 1912.

Beguería, S., Vicente-Serrano, S. M., Reig, F. \& Latorre, B. (2014). Standardized precipitation evapotranspiration index (SPEI) revisited: parameter fitting, evapotranspiration models, tools, datasets and drought 
monitoring. International Journal of Climatology, 34, 3001-3023.

Benjamini, Y. \& Hochberg, Y. (1995). Controlling the false discovery rate: A practical and powerful approach to multiple testing. Journal of the Royal Statistical Society, series B, 57, 289-300.

Beck, C., Philipp, A., \& Jacobeit, J. (2015). Interannual drought index variations in Central Europe related to the large-scale atmospheric circulation - application and evaluation of statistical downscaling approaches based on circulation type classifications. Theorical and Applied Climatology, 121, 713-732.

Blöschl, G., Hall, J., Viglione, A., Perdigão, R. A., Parajka, J., Merz, B., .. \& Boháč, M. (2019). Changing climate both increases and decreases European river floods. Nature, 573(7772), 108-111

Bormann, H. \& Pinter, N. (2017). Trends in low flows of German rivers since 1950: Comparability of different low-flow indicators and their spatial patterns. River Research and Applications, 33, 1191- 1204.

Burn, D.H. (1997). Catchment similarity for regional flood frequency analysis using seasonality measures. Journal of Hydrology, 202, 212-230.

Coch, A., \& Mediero, L. (2016). Trends in low flows in Spain in the period 1949-2009, Hydrological Sciences Journal, 61:3, 568-584.

Costigan, K., Kennard M., Leigh C., Sauquet E., Datry T., \& Boulton A.J. (2017). Chapter 2.2 - Flow regimes in intermittent rivers and ephemeral streams. In: "Datry T., Bonada N. \& Boulton A.J. (Eds.), Intermittent Rivers and Ephemeral Streams. Ecology and Management", Academic Press (pp. 51-78). doi: 10.1016/c2015-0-00459-2.

Datry, T., Singer, G., Sauquet, E., Jorda-Capdevilla, D., Von Schiller, D., Subbington, R., Magand, C., Par̆il, P., Miliša, M., Acuña, V., Alves, M., Augeard, B., Brunke, M., Cid, N., Csabai, Z., England, J., Froebrich, J., Koundouri, P., Lamouroux, N., Martí, E., Morais, M., Munné, A., Mutz, M., Pesic, V., Previšić, A., Reynaud, A., Robinson, C., Sadler, J., Skoulikidis, N., Terrier, B., Tockner, K., Vesely, D., \& Zoppini, A. (2017). Science and Management of Intermittent Rivers and Ephemeral Streams (SMIRES). Research Ideas and Outcomes 3: e21774.https://doi.org/10.3897/rio.3.e21774

De Girolamo, A.M., Bouroui, F., Buffagni, A., Pappagallo, G., \& Lo Porto, A. (2017). Hydrology under climate change in a temporary river system: Potential impact on water balance and flow regime. River Research and Applications, 33, 1219-1232.

Delso, J., Magdaleno, F., Fernández-Yuste, J.A. (2017). Flow patterns in temporary rivers: a methodological approach applied to southern Iberia. Hydrological Sciences Journal, 62:10, 1551-1563,

Dörflinger, G. (2016). A new spatial basis for rivers monitoring and management in Cyprus. DProf thesis. Middlesex University. [online]. Available from: http://eprints.mdx.ac.uk/20817/ [Accessed January 15, 2020].

Eng, K., Wolock, D. M., and Dettinger, M. D. (2016). Sensitivity of Intermittent Streams to Climate Variations in the USA. River Reseach and Applications, 32, 885-895.

Gallart, F., \& Llorens, P. (2004). Observations on land cover changes and water resources in the headwaters of the Ebro catchment, Iberian Peninsula. Physics and Chemistry of the Earth, parts A/B/C, 29(11-12), 769-773.

Gallart, F., Amaxidis, Y., Botti, P., Canè, G., Castillo, V., Chapman, P., ..., Tournoud, M.G. (2010). Investigating hydrological regimes and processes in a set of catchments with temporary waters in Mediterranean Europe. Hydrological Sciences Journal, 53:3, 618-628.

Giuntoli I., Renard, B., Vidal, J.-P., \& Bard, A. (2013). Low flows in France and their relationship to large scale climate indices. Journal of Hydrology, 482, 105-118

Gustard, A., Bullock, A., \& Dixon, J.M. (1992). Low flow estimation in the United Kingdom. Report N 108 , Institute of Hydrology, Wallingford, UK. 292p. 
Hamed, K. H. \& Rao, A. R. (1998). A modified Mann-Kendall trend test for autocorrelated data, Journal of Hydrology, 204, 182-196.

Hannaford, J., Lloyd-Hughes, B., Keef, C., Parry, S. \& Prudhomme, C., (2011). Examining the large-scale spatial coherence of European drought using regional indicators of precipitation and streamflow deficit. Hydrological Processes, 25: 1146-1162.

Hertig, E., \& Tramblay, Y. (2017). Regional downscaling of Mediterranean droughts under past and future climatic conditions. Global and Planetary Change, 151, 36-48.

Hurrell, J.W., \& Folland, C.K. (2002). The relationship between tropical Atlantic rainfall and the summer circulation over the North Atlantic. CLIVAR Exchanges, 25, 52-54

Ionita, M., Tallaksen, L. M., Kingston, D. G., Stagge, J. H., Laaha, G., Van Lanen, H. A. J., Scholz, P., Chelcea, S. M., \& Haslinger, K. (2017). The European 2015 drought from a climatological perspective. Hydrology and Earth System Sciences, 21, 1397-1419.

Kennard, M.J., Pusey, B.J. Olden, J.D., Mackay, S.J., Stein, J.L., \& Marsh, N. (2010). Classification of natural flow regimes in Australia to support environmental flow management. Freshwater Biology, 55, 171193.

Kirkby, M. J., Gallart, F., Kjeldsen, T. R., Irvine, B. J., Froebrich, J., Porto, A. L., \& Girolamo, A. D. (2011). Classifying low flow hydrological regimes at a regional scale. Hydrology and Earth System Sciences, 15(12), 3741-3750.

Laaha, G., Gauster, T., Tallaksen, L. M., Vidal, J.-P., Stahl, K., Prudhomme, C., Heudorfer, B., Vlnas, R., Ionita, M., Van Lanen, H. A. J., Adler, M.-J., Caillouet, L., Delus, C., Fendekova, M., Gailliez, S., Hannaford, J., Kingston, D., Van Loon, A. F., Mediero, L., Osuch, M., Romanowicz, R., Sauquet, E., Stagge, J. H., \& Wong, W. K., (2017). The European 2015 drought from a hydrological perspective. Hydrology and Earth System Sciences, 21, 3001-3024.

Linderholm, H. W., Folland, C. K. \& Walther, A. (2009). A multicentury perspective on the summer North Atlantic Oscillation (SNAO) and drought in the eastern Atlantic Region. Journal of Quaternary Science, 24, $415-425$.

Mann, H. B. (1945). Nonparametric tests against trend. Econometrica, 13,245- 259.

McKee, T. B., N. J. Doesken, \& Kleist, J. (1993). The relationship of drought frequency and duration to time scales. Preprints, Eighth Conf. on Applied Climatology. Anaheim, CA, Amer. Meteor. Soc., 179-184.

Myronidis, D., Ioannou, K., Fotakis, D. \& Dörflinger, G. (2018). Streamflow and Hydrological Drought Trend Analysis and Forecasting in Cyprus. Water Resources Management, 32, 1-18.

Osuch, M., Romanowicz, R.J., Lawrence, D., \& Wong, W.K. (2016). Trends in projections of Standardized Precipitation Indices in a future climate in Poland. Hydrology and Earth System Sciences, 20, 1947-1969.

Osuch, M., Romanowicz, R.J., \& Wong, W.K. (2018). Analysis of low flow indices under varying climatic conditions in Poland. Hydrology Research, 49 (2): 373-389.

Oueslati, O., De Girolamo, A. M., Abouabdillah, A., Kjeldsen, T. R., \& Lo Porto, A., (2015). Classifying the flow regimes of Mediterranean streams using multivariate analysis. Hydrological Processes, 29: 4666-4682.

Perez-Saez, J., Mande, T., Larsen, J., Ceperley, N., \& Rinaldo, A., (2017). Classification and prediction of river network ephemerality and its relevance for waterborne disease epidemiology. Advances in Water Resources, 110, 263-278.

Pournasiri Poshtiri, M., Pal, I., Lall, U., Naveau, P., \& Towler, E. (2019). Variability patterns of the annual frequency and timing of low streamflow days across the United States and their linkage to regional and large-scale climate. Hydrological Processes, 33, 1569- 1578. 
Skoulikidis, N.T., Sabater, S., Datry, T., Morais, M.M., Buffagni, A., Dorflinger, G., ..., \& Tockner, C. (2017). Non-perennial Mediterranean rivers in Europe: Status, pressures, and challenges for research and management. Science of the Total Environment, 577, 1-18.

Snelder, T. H., Datry, T., Lamouroux, N., Larned, S. T., Sauquet, E., Pella, H., \& Catalogne, C. (2013). Regionalization of patterns of flow intermittence from gauging station records, Hydrology and Earth System Sciences, 17, 2685-2699.

Stahl K., \& Demuth S. (1999). Linking streamflow drought to the occurrence of atmospheric circulation patterns. Hydrological Sciences Journal, 44, 467-482.

Stahl, K., Hisdal, H., Hannaford, J., Tallaksen, L. M., van Lanen, H. A. J., Sauquet, E., Demuth, S., Fendekova, M., \& Jodar, J. (2010). Streamflow trends in Europe: evidence from a dataset of near-natural catchments. Hydrology and Earth System Sciences, 14, 2367-2382.

Spinoni, J., Naumann, G., Vogt, J.J. (2017). Pan-European seasonal trends and recent changes of drought frequency and severity. Global and Planetary Changes, 148, 113-130.

Tzoraki, O., Girolamo, A.M., Gamvroudis, Ch., Skoulikidis, N. (2016). Assessing the Flow alteration of temporary streams under current conditions and changing climate by SWAT model. International Journal of River Basin Management, 14, 1571-5124.

Tramblay, Y., St-Hilaire, A., Ouarda, T., Moatar, F., \& Hecht, B. (2010). Estimation of local extreme suspended sediment concentrations in California Rivers. Science of the total environment, 408, 4221-4229.

Vicente-Serrano, S.M., Begueria, S., \& Lopez-Moreno, J.I. (2010). A multiscalar drought index sensitive to global warming: the standardized precipitation evapotranspiration index - SPEI. Journal of Climate, 23, 1696-1718.

Valty, P., de Viron, O., Panet, I., \& Collilieux, X. (2015). Impact of the North Atlantic Oscillation on Southern Europe Water Distribution: Insights from Geodetic Data. Earth Interactions, 19, DOI: 10.1175/EID-14-0028.1.

Wilks, D.S. (2016). The stippling shows statistically significant grid points: how research results are routinely overstated and over interpreted, and what to do about it. Bulletin of the American Meteorological Society, $97,2263-2273$.

Wrzesiński, D, \& Paluszkiewicz, R. (2011). Spatial differences in the impact of the North Atlantic Oscillation on the flow of rivers in Europe. Hydrology Research, 42, 30-39.

\section{TABLES}

Table 1: Summary of the detected trends in the annual and seasonal number of zero flow days and the maximum length of dry spells

\begin{tabular}{lll}
\hline Variable & Positive trends & Negative trends \\
\hline Annual sum & $23,62 \%$ & $10,24 \%$ \\
Annual maximum & $20,08 \%$ & $8,66 \%$ \\
Winter sum & $10,63 \%$ & $8,66 \%$ \\
Winter maximum & $23,23 \%$ & $9,45 \%$ \\
Summer sum & $23,62 \%$ & $6,69 \%$ \\
Summer maximum & $18,11 \%$ & $9,45 \%$ \\
\hline
\end{tabular}

Table 2: Percentage of catchments with significant correlations $(\alpha=0.05)$ between seasonal metrics of intermittence and large-scale climate drivers. The subscripts $s, w$, DJF, JJA, w1refer to the summer (AprSep), winter (Sep-Mar), Dec-Feb, Jun-Aug, and winter from the preceding year, respectively. 


\begin{tabular}{|c|c|c|c|c|c|}
\hline a) & Positive correlations & Positive correlations & Negative correlations & b) & Positive correlations \\
\hline variable & $\mathrm{AMO}_{\mathrm{s}}$ & $\mathrm{AMO}_{\mathrm{w}}$ & $\mathrm{NAO}_{\mathrm{DJF}}$ & variable & $\mathrm{NAO}_{\text {JJA }}$ \\
\hline winter max & $18 \%$ & $16 \%$ & $11 \%$ & summer max & $11 \%$ \\
\hline winter sum & $21 \%$ & $19 \%$ & $11 \%$ & summer sum & $9 \%$ \\
\hline
\end{tabular}

\section{FIGURES CAPTIONS}

Figure 1: Mean annual percentage of zero-flow days at the annual, summer and winter timescales

Figure 2: Results of the cluster analysis on zero-flow seasonality. Colours represent seasonality of zero-flow events. Blue colour denotes stations with zero-flow events observed from November to January. Red colour indicates zero-flow events in summer while green colour in the period between January and March

Figure 3: Significant increasing (later date) or decreasing (earlier date) trends in the mean date of zero-flow day occurrence, at the $10 \%$ significance level

Figure 4: Significant increasing (red triangle up) or decreasing (blue triangle down) trends, at the $10 \%$ significance level, for the annual or seasonal mean number of zero flow days (left), the annual or seasonal maximum length of dry spells (right)

Figure 5: Relative number of significant correlations at the $5 \%$ level between annual, summer and winter sum of zero flow days, and maximum length of dry periods with SPEI6, SPEI12, SPEI18 and SPEI24

Figure 6: Map of the significant correlations between the annual sum of zero flow days (top) and annual maximum length of zero flow days (bottom) with the SPEI18. The black crosses indicate stations where the correlation is not significant at the $10 \%$ level. Correlations are negative because the smaller the SPEI (water deficit), the larger the number of zero-flow days.

Figure 7: Correlations between the summer sum of zero-flow days and summer AMO (left), and the correlation between the winter sum of zero-flow days with winter NAO (right)
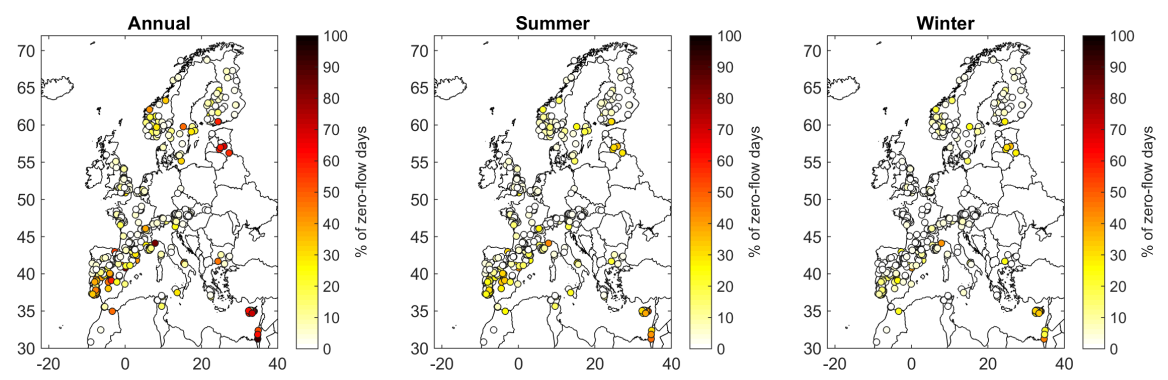

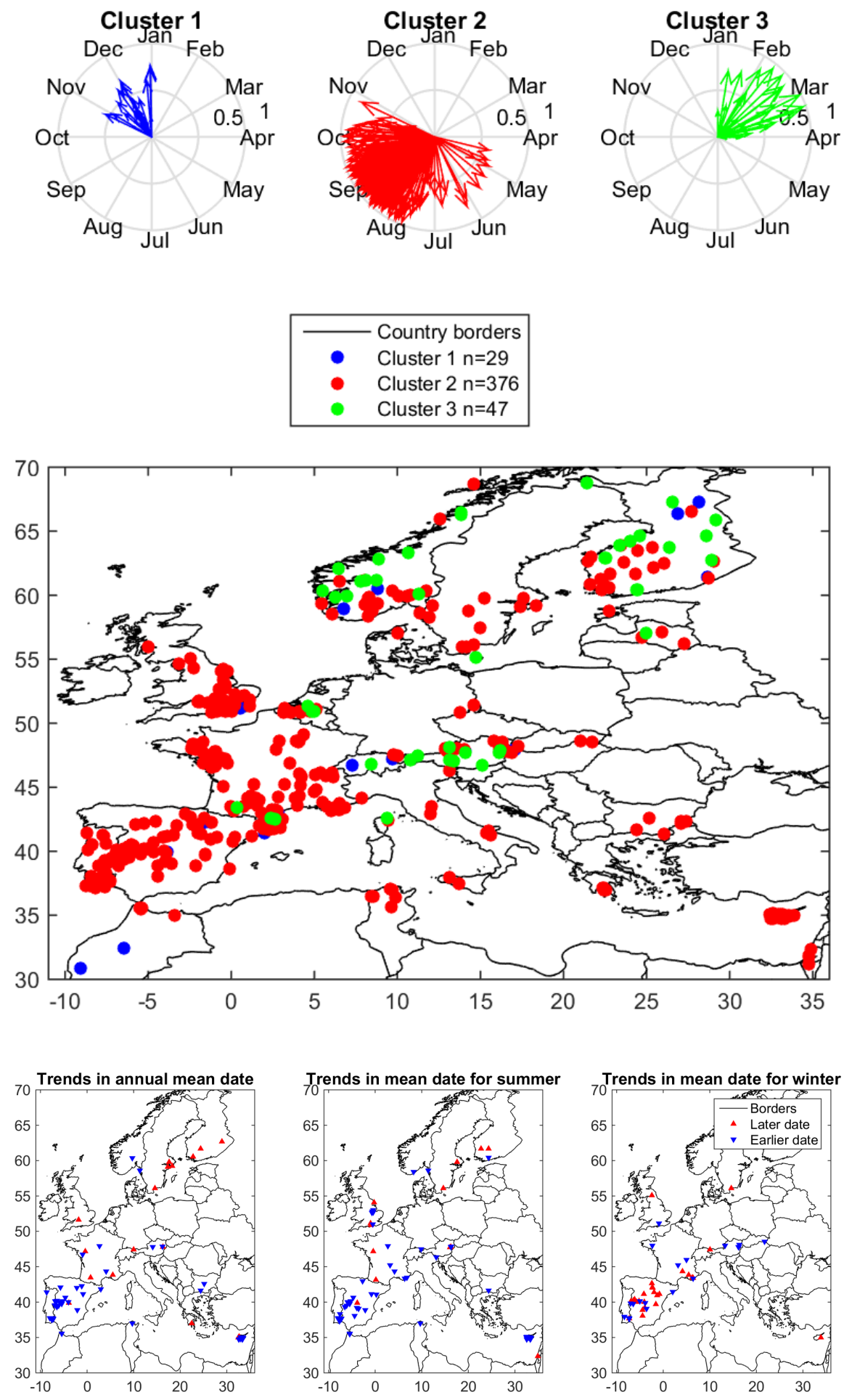


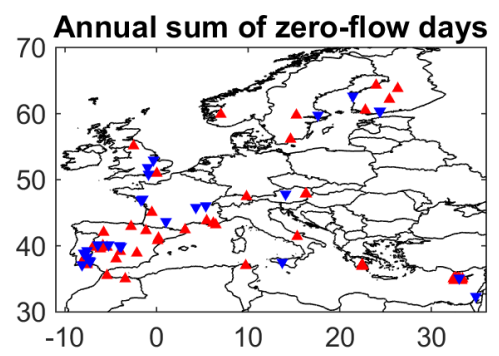

Annual maximum length of zero-flow days
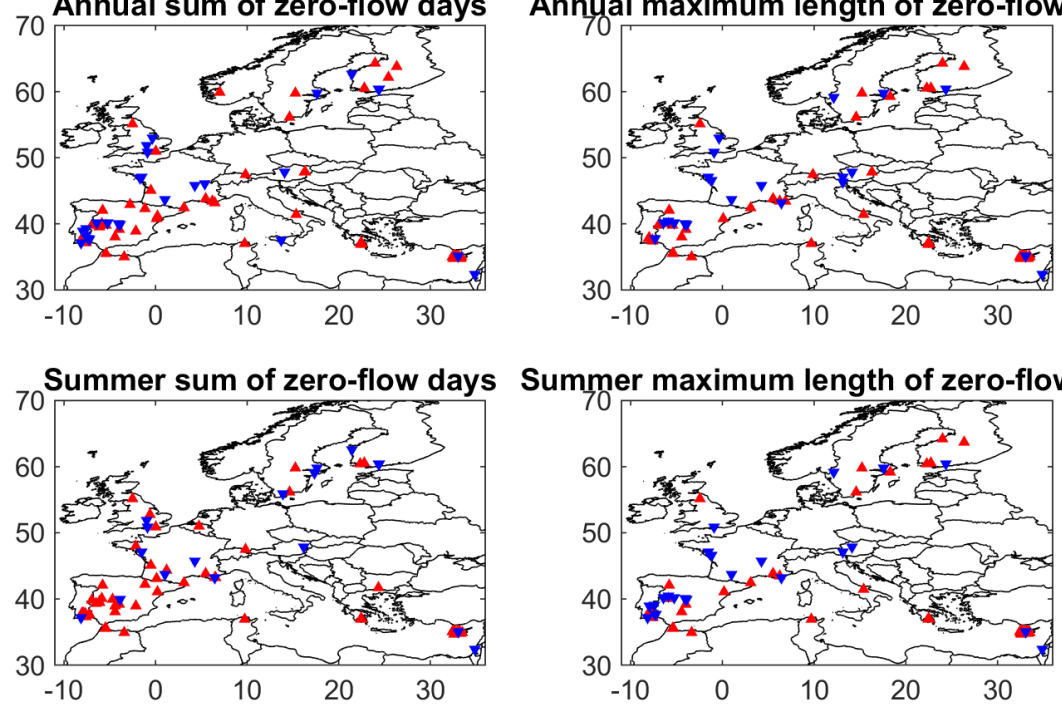

Summer maximum length of zero-flow days
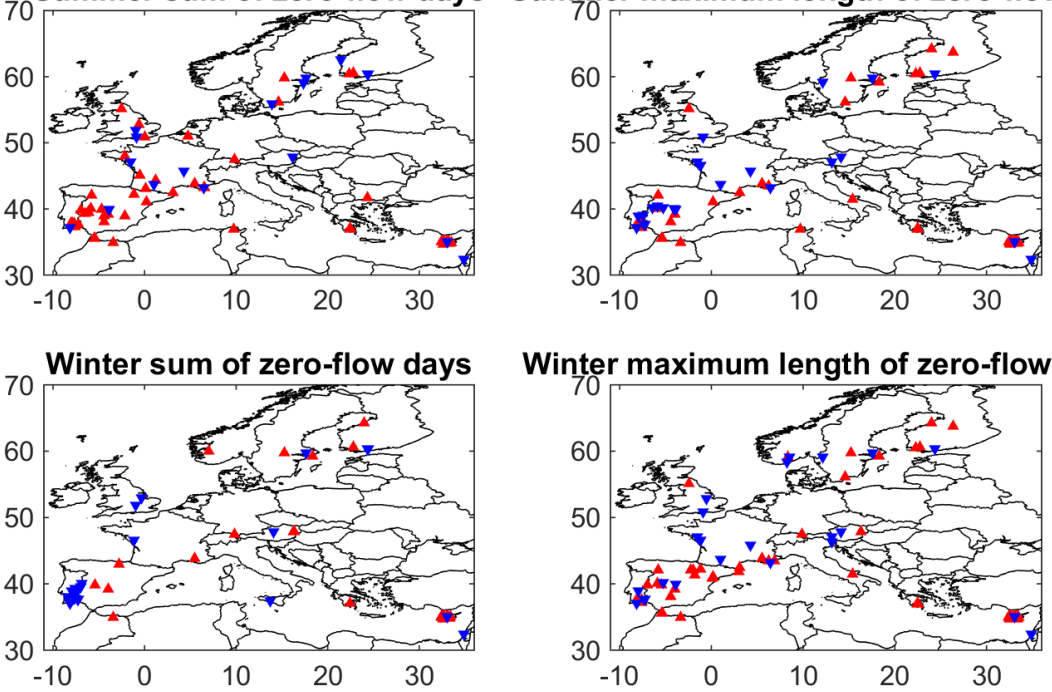

Winter maximum length of zero-flow days

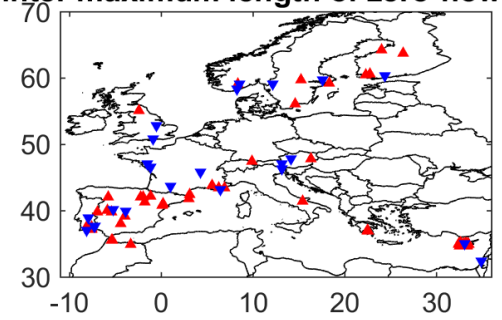




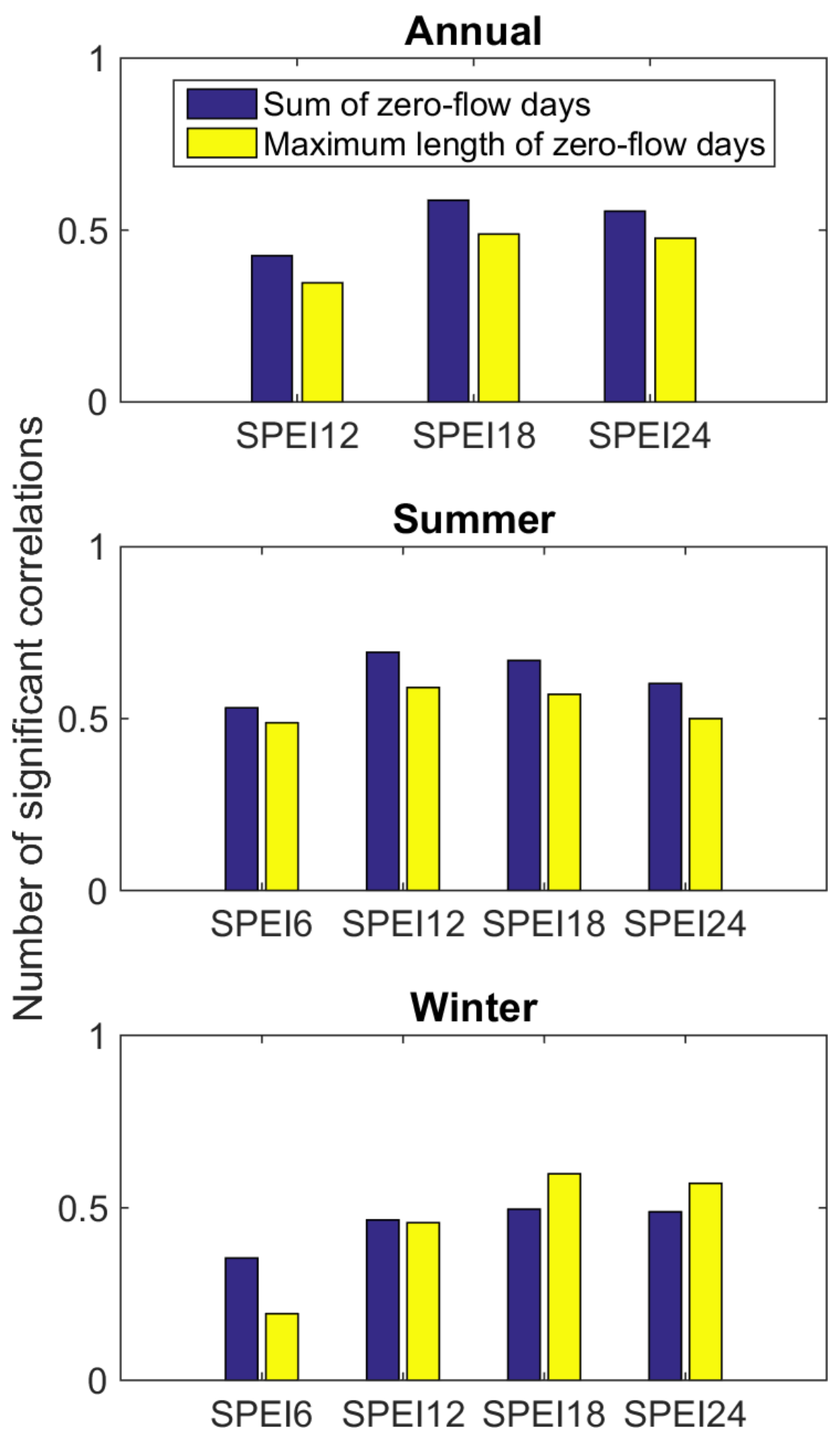


Correlation between annual sum

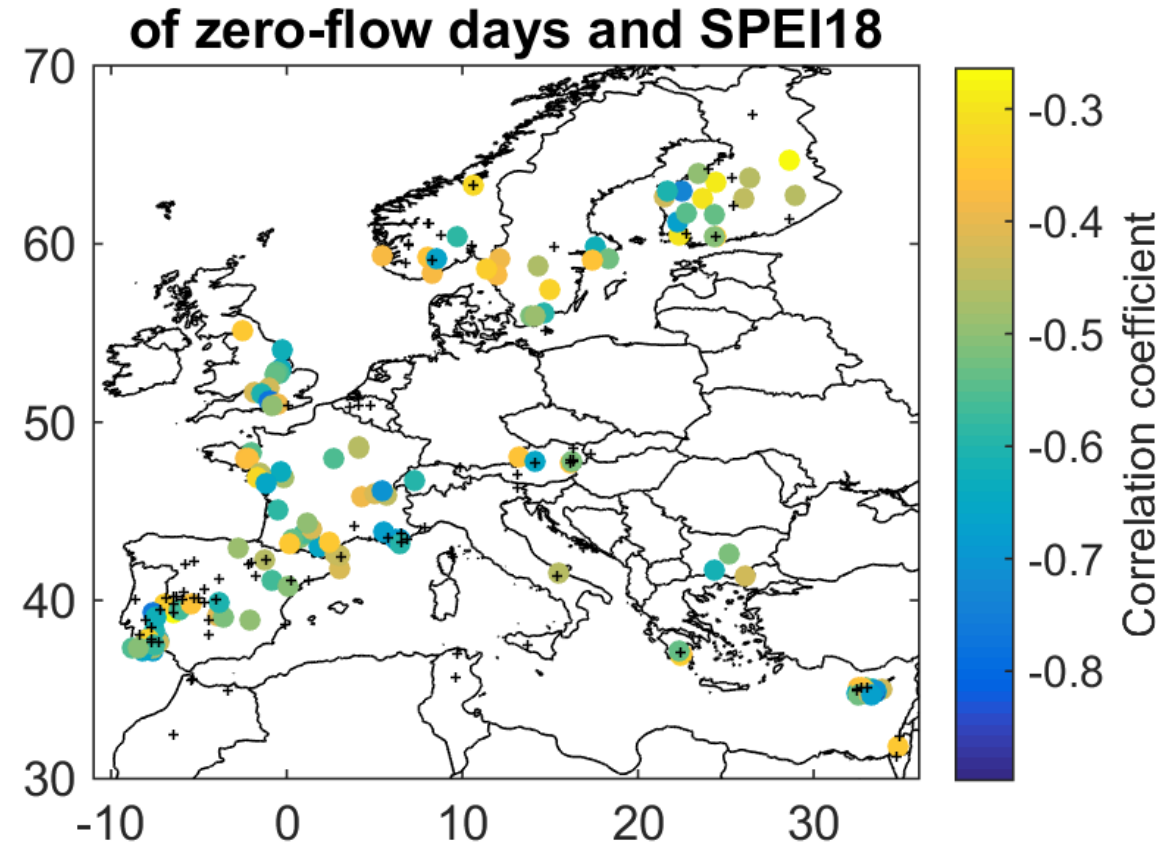

Correlation between annual maximum length of zero-flow days and SPEI18

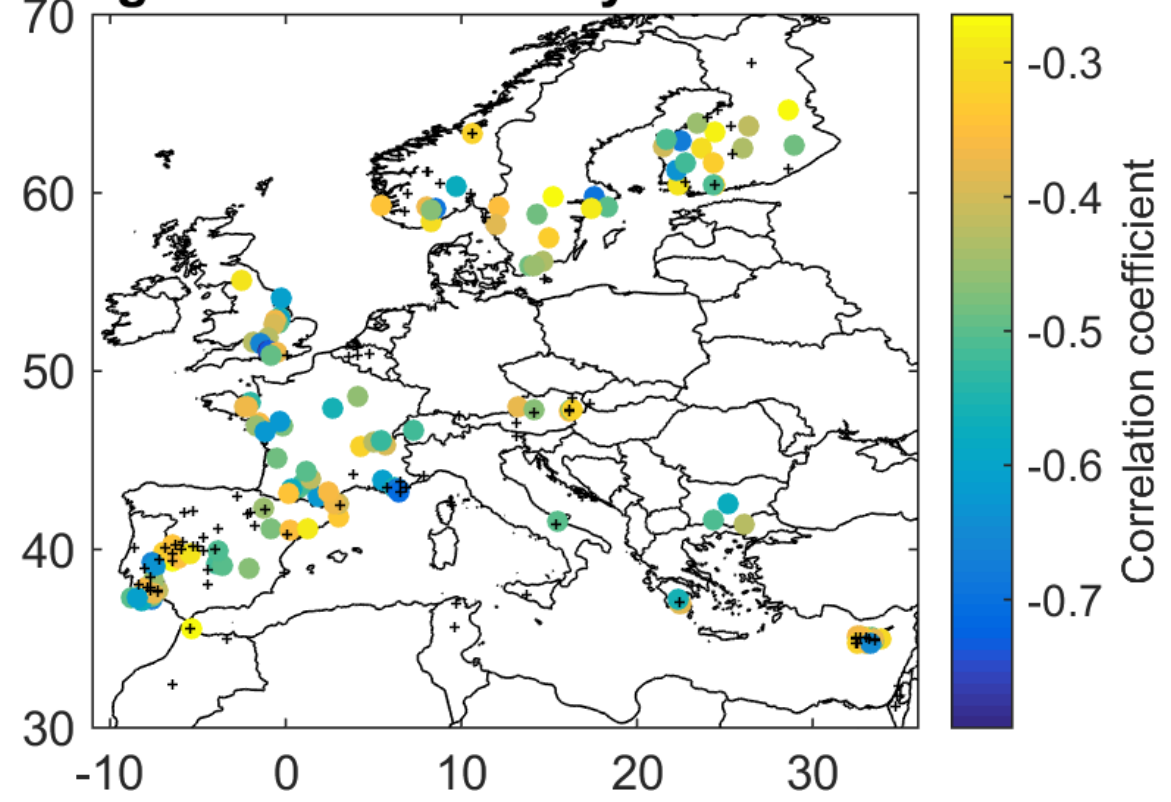




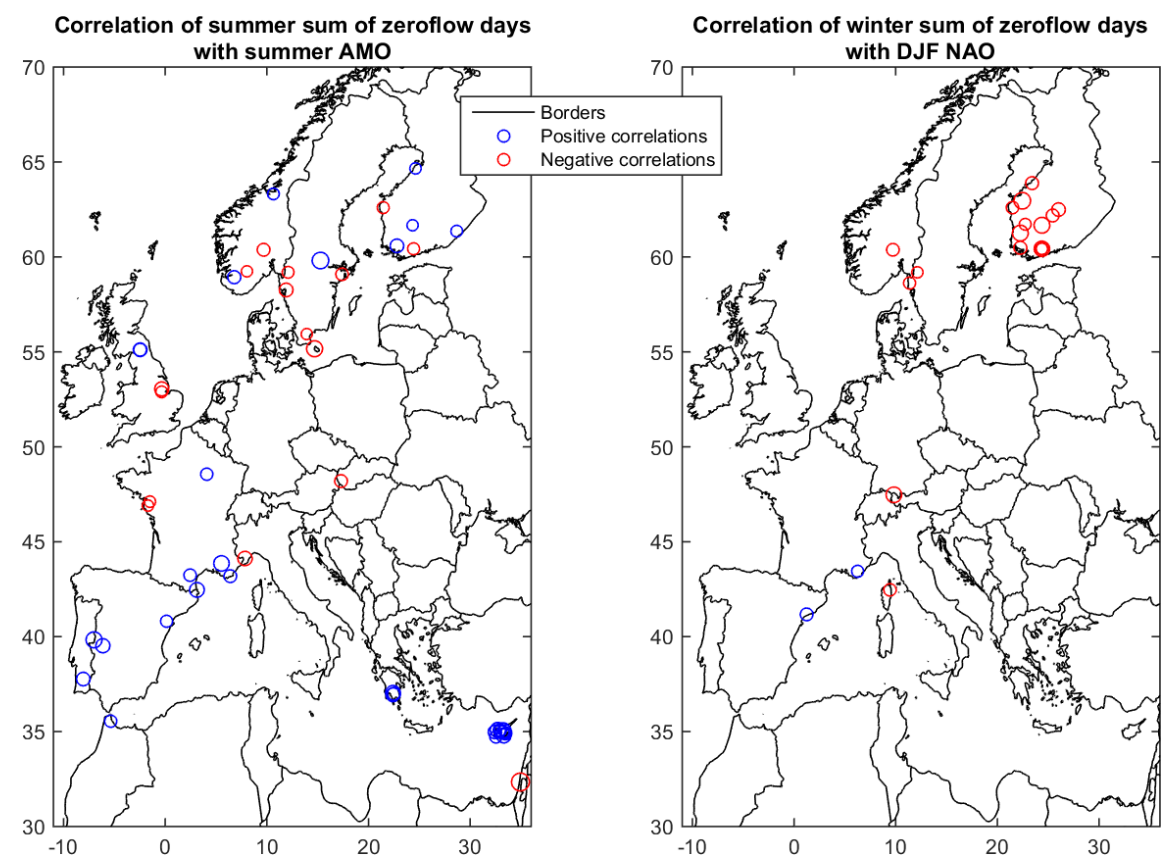

